\title{
Caffeine Measurement
}

National Cancer Institute

\section{Source}

National Cancer Institute. Caffeine Measurement. NCI Thesaurus. Code C75346.

The determination of the amount of caffeine present in a sample. 